\title{
Feasibility of Real-Time Mobile Phone Case Notification by Village Malaria Workers in Rural Myanmar: A Mixed Methods Study
}

\author{
Pyae Linn Aung ${ }^{1}$, Tepanata Pumpaibool ${ }^{1}$, Than Naing Soe ${ }^{2} \&$ Myat Phone Kyaw ${ }^{3}$ \\ ${ }^{1}$ College of Public Health Science, Chulalongkorn University, Bangkok, Thailand \\ ${ }^{2}$ Disease Control, Department of Public Health, Naypyitaw, Myanmar \\ ${ }^{3}$ Department of Medical Research, Lower Myanmar \\ Correspondence: Tepanata Pumpaibool and Pyae Linn Aung, College of Public Health Science, Chulalongkorn \\ University, Bangkok, 11330, Thailand. E-mail: Tepanata.P@chula.ac.th; pyaelinnag@gmail.com
}

Received: November 7, 2018 Accepted: December 4, 2018 Online Published: December 18, 2018

doi:10.5539/gjhs.v11n1p103 URL: https://doi.org/10.5539/gjhs.v11n1p103

\begin{abstract}
Malaria burden has markedly decreased in Myanmar and is on course for elimination by 2030. Interrupting of local transmission is essential, and timely notification within 24 hours of disease occurrence by frontline village malaria workers (VMWs) is a crucial initial component of timely follow-up by response teams. Here we studied the feasibility of real-time case notification using mobile phones among VMWs in the remote Banmauk Township, Sagaing Region, Myanmar. A structured quantitative and qualitative questionnaire was used for data collection after implementing the intervention for six months between May and October 2018. Ten VMWs from the National Malaria Control Programme (NMCP) in ten scattered villages from the township were randomly recruited and given one day of on-site training on reporting methods and how to use their own mobile phone. VMWs received 5,000MMK (approximately 3USD) per month remuneration. The baseline demographics of VMWs were not significantly different. Twenty-four out of $25(96 \%)$ malaria patients were notified within 24 hours by the ten VMWs during the study period. All submitted information were said to be complete and correct. VMWs suggested the system as simple and acceptable despite some challenges. In the qualitative study, almost all VMWs were satisfied with the system and willing to use it in the future. This mobile phone reporting system is more efficient and easier to use than other more complicated online mobile applications. However, only a few indicators can be submitted using this approach and the system cannot be used in areas without network coverage.
\end{abstract}

Keywords: real-time reporting, mobile Phone, case Notification, village malaria workers, Myanmar

\section{Introduction}

Despite markedly decreasing trends of both malaria morbidity and mortality, in 2016, around 43 millions of people are still living in 291 malaria endemic townships out of 330 in Myanmar. Among them, almost 105,000 cases have been confirmed malaria when 21 deaths were recorded (Department of Public Health [DOPH], 2016; World Health Organization [WHO], 2017). It drastically declined in compare with 1,707 deaths and 516,041 cases of malaria from 2010 (DOPH, 2016). Thus, Myanmar is now on course for elimination by 2030. In the elimination phase, the country should concentrate on detecting every symptomatic and asymptomatic infections and reacting to every confirmed case. Once a local case of malaria has been found and notified, a focus investigation is carried out by malaria staff within 72 hours ( 3 days) to describe the locality where malaria occurred for determining the underlying causes of ongoing transmission, and rapid measures (responses) should be applied in a given focus as early as possible but not later than 7 days to interrupt transmission and prevent its further spread (Cao et al., 2014; Feng et al., 2016; Wang et al., 2017). This particular can be handled by a township level malaria rapid response team (DOPH, 2016; WHO, 2012). Recording and reporting mechanisms and the systems within existing public, private and community-based health sectors should be established to address elimination challenges by timely detecting and immediately notifying the malaria programme of all confirmed cases by the fastest means possible. Although some kinds of smart phone based reporting system like DHIS-II and M-health have been introducing in Myanmar since 2017, overall coverage area is still low as in pilot stage and acceptability among providers is still trying to encourage (DOPH, 2016).

Again, the goal of eliminating malaria in Myanmar is more distant because the rapidity in achieving the declared 
goal is influenced by the relatively high burden of malaria, the suboptimal development of national health systems and technical and operational constraints (resistance to antimalarial drugs, vector behaviours, accessibility of remote/border areas, uncontrolled migration etc.). In areas with poor public health infrastructure and services, the establishment of a network of Village Malaria Workers (VMWs) is the best and often only option to reach the total coverage of curative and preventive services, in order to detect, notify and treat every malaria infection in a proper and timely manner (Phommanivong et al., 2010). Currently in Myanmar, over 15,000 VMWs are scattering around the country and supported by 24 different implementing organizations including Vector Borne Disease Control (VBDC) team under National Malaria Control Programme (NMCP) (WHO, 2017; Myanmar Information Management Unit, 2018). Thus, while interrupting of local transmission is essential, timely notification within 24 hours of disease occurrence by frontline village malaria workers (VMWs) become a crucial initial component of timely follow-up by response teams. Globally, studies have found that mobile phone based malaria reporting system is an acceptable and feasible intervention for lay health workers and one that can significantly affect program operations and malaria transmission rates (Hamainza et al., 2014; Kukula et al., 2015; Meankaew et al., 2010; Kamanga et al., 2010). However, feasibility, acceptability and data quality should be assured while simple style of intervention is encouraged (Prue et al., 2013; Rassi et al., 2018).

In Myanmar, mobile SIM cards were not freely available and even cost more than hundreds of dollars until 2013. But since then, it has been transformed and become cheaper and cheaper as less than 2 USD in 2015 (LIRNE Asia, 2017). Nowadays, SIMs are freely available across the country and $90 \%$ of areas have network signal coverage. In $2015,40 \%$ of total population owned a mobile phone (Galpaya, Zainudeen \& Suthaharan, 2015). According to universal service strategy for Myanmar (2018-2022), most of the people (90\%) will be covered by network and among them, around 85\% will have internet access by 2022 (Post and Telecom Department, 2018). Particularly in Sagaing Region, only $4.2 \%$ of the area are uncovered by facility as of January 2018 (Zainudeen \& Galpaya, 2015). To take advantage from this, in this study, a simple mobile phone reporting system was introduced among VMWs and evaluated from the aspects of timeliness of reporting, correctness and completeness of information, preference and challenges on using the system and acceptability for the future. Hence, this study will contribute evidence for the feasibility of real-time case notification using mobile phones among VMWs in the remote Banmauk Township, Sagaing Region, Myanmar, where real time reporting is rare but technology literacy is relatively high.

\section{Methods}

This study was conducted in ten villages of Banmauk Township, Sagaing Region, Myanmar. The township is located in the upper region of the country and consists of 223 villages. Four different organisations are performing intensive malaria control activities under the sponsorship of different donors. However, the Vector Borne Disease Control (VBDC) team of the National Malaria Control Programme (NMCP) under the supervision of the Township Medical Officer (TMO) plays an administrative and collaborative role and ensures that these activities do not overlap and that all villages are included. In general, the VMWs were residents of the various villages and were recruited on a voluntary basis after being nominated by the local authorities. After receiving five days of recruitment training, they were assigned to conduct malaria diagnosis and treatment and route data recording into carbonless paper report. They also participate in three days of annual refresher training. Malaria commodities, including rapid diagnostic tests (combo RDTs), artemisinin-based combination therapy (Artemeter plus Lumefantrine) tablets, disposable gloves, safety boxes, and behavioural change communication materials, such as pamphlets and posters, were distributed through a township-level supply chain. Monthly monitoring and supervision visits were also routinely conducted by the VBDC team, which relied on a standard checklist. 


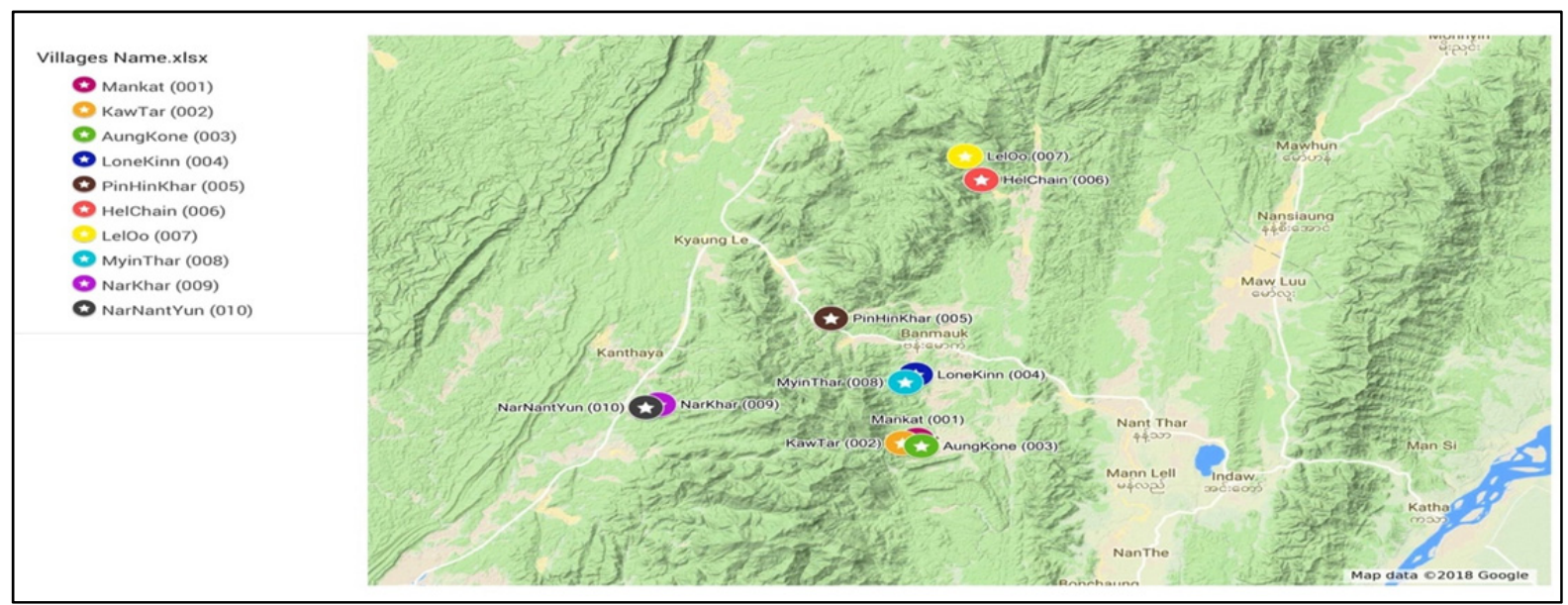

Figure 1. The ten study villages in Banmauk Township, Sagaing Region, Myanmar

As study participants, ten out of 50 VMWs trained and supported by VBDC team in ten scattered villages (Figure 1) from the township were randomly recruited and given one day of on-site training on reporting methods and how to use their own mobile phone along with the practical session. A hot-line number was provided and saved into their phone contact list. From each malaria patient, necessary information to be addressed for briefly case classification and also for routing surveillance purpose, date \& time of diagnosis, age, sex, parasite species, travelling history and treatment given were collected and reported through a call. There was an assigned field supervisor at township level and responsible for receiving calls and recording of data from each VMW into a checklist paper. Then data were translated into English language, entry into computer and back up regularly into a password protected hard disk. (Figure 2) As a regular incentive, 5,000MMK (approximately 3USD) per month remuneration was provided. At the end of each month, the mobile bill has been directly filled with e-load system into registered number of each volunteer and ensured of receipt by a call. It is like a standard amount and regular top up regardless of number of patients found.

In addition to the data tracking checklist, a structured quantitative and qualitative questionnaire was used for data collection after implementing the intervention for six months between May and October 2018. It constructed with two parts; the quantitative part consisted of demographic characteristics of each VMW, simplicity of system, their acceptability, preferences and other challenges. The qualitative part explored for their overall comments as well as suggestions on this reporting system. At the end of October, data were collected at their village with the help of two graduated data collectors. In the meantime, the compiled data from checklist were cross-checked with their field carbonless data entry. Feedback on any discrepancies was provided and supported of solutions during monthly monitoring visit as well as at the end of project. Timeliness, correctness and overall completeness were also concluded. At the beginning of project, consent form was requested and signed by each VMW and for the ethical issue, this study was reviewed and approved by the Institutional Technical and Ethical Review Board, University of Public Health - Yangon, Ministry of Health \& Sports (UPH-IRB 2018/Research/29). Data were encoded, entry and analysed by Microsoft excel 2015 for descriptive statistics. 
Trained VMWs performed malaria diagnosis and treatment in the village, timely notification of RDT (+) cases within 24 hours through mobile phone

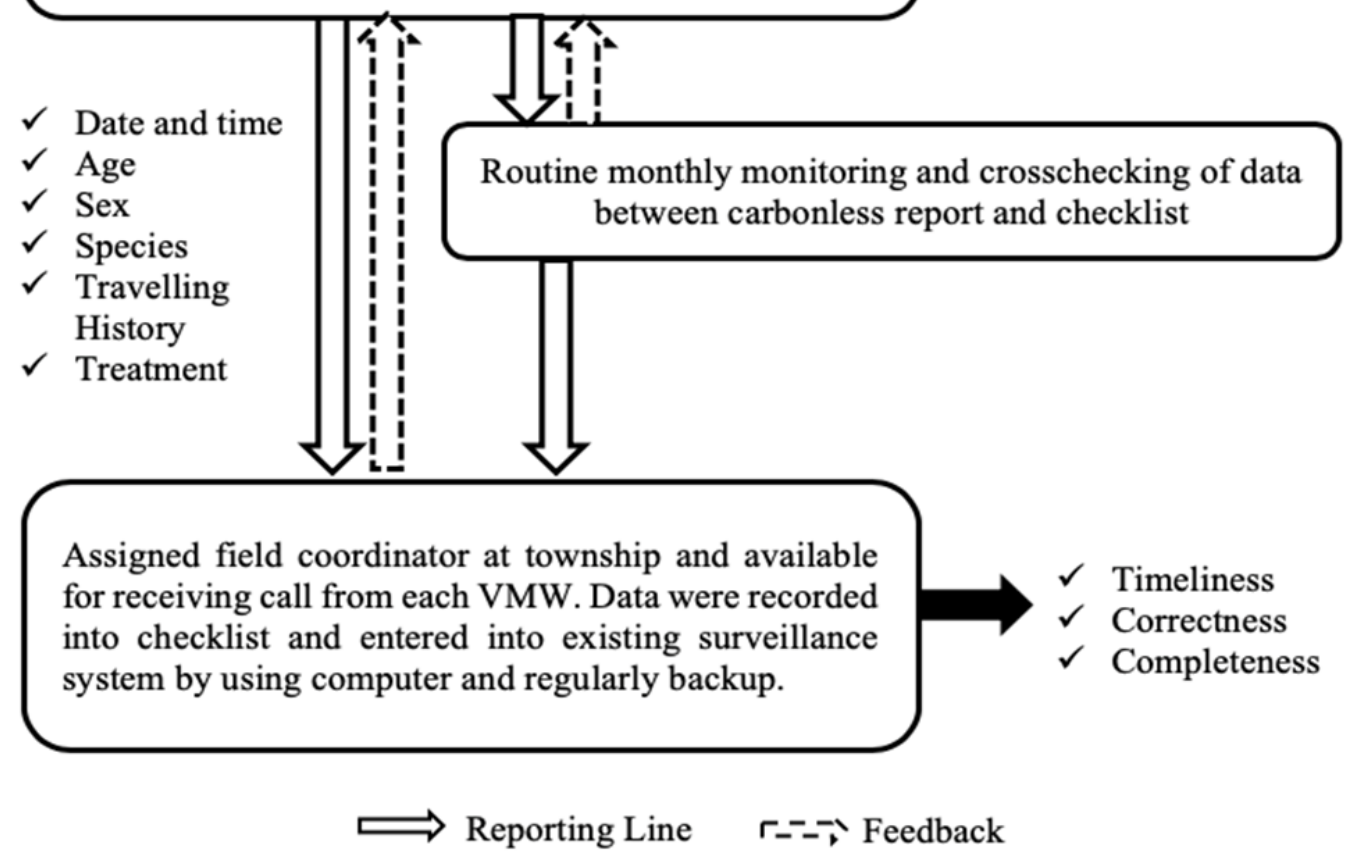

Figure 2. Mobile phone reporting system flow chart

\section{Results}

First, the baseline demographic characteristics of VMWs are reported in Table 1, revealing similar distribution of age, sex, and family income among study participants. Moreover, majority of the respondents are educated at the primary school level (70.0\%), and while all the VMWs possess a mobile phone, $90 \%$ are using smart phone. During the study period, 24 of the 25 malaria patients $(96 \%)$ were notified within 24 hours by the ten VMWs. Two $(8.0 \%)$ of these cases were reported within $10-15$ hours, while most of the remaining patients $(88.0 \%)$ could be informed within 1 hour from the diagnosis. Unfortunately, there was a delayed case notification only after 24 hours. (Figure 3)

Table 1. Baseline demographic characteristics of VMWs $(n=10)$

\begin{tabular}{lll}
\hline Characteristics & Frequency & Percentage (\%) \\
\hline Age & 4 & \\
$\quad<30$ Years & 6 & 40.0 \\
$>30$ Years & $28.5 \pm 5.3$ & 60.0 \\
$\quad$ Mean \pm SD & & \\
Sex & 4 & 40.0 \\
$\quad$ Male & 6 & 60.0 \\
$\quad$ Female & & \\
Family Income & 4 & 40.0 \\
$\quad$ Enough & 6 & 60.0 \\
$\quad$ Not enough & & \\
Education & &
\end{tabular}


Primary School

Above primary school

Ownership a mobile phone

$$
\text { Yes }
$$

No

Types of mobile handset

Smart Phone (Touch Screen)

Key-pad

$\begin{array}{ll}7 & 70.0 \\ 3 & 30.0\end{array}$

$10 \quad 100$

0

990.0

$1 \quad 10.0$

*SD=Standard deviation.

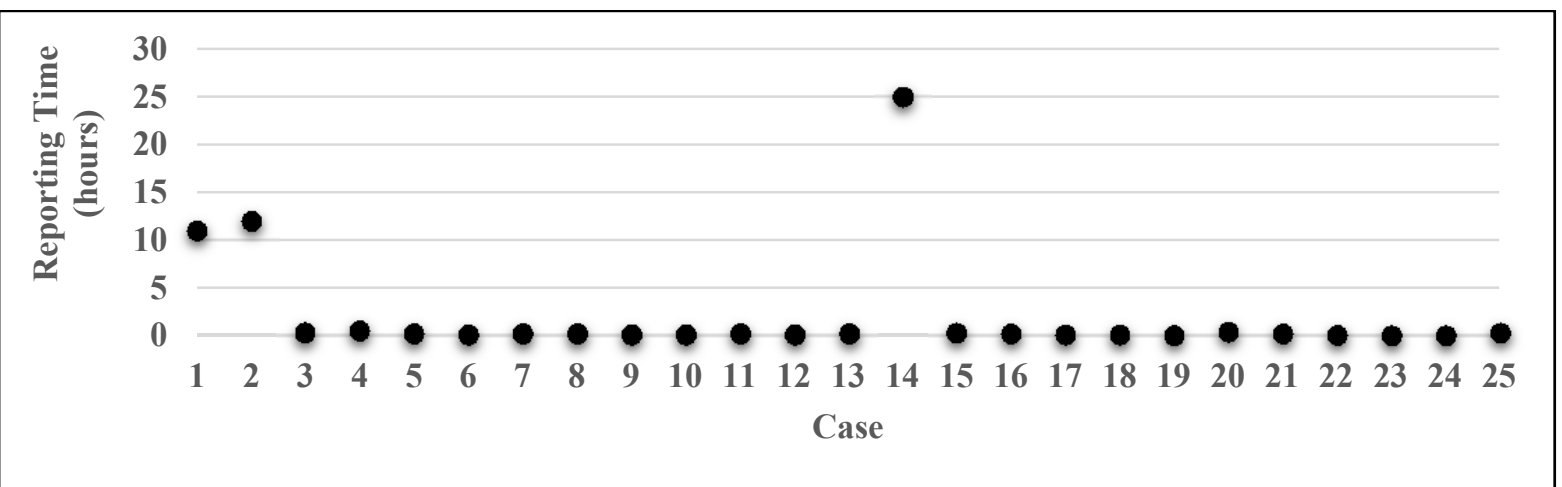

Figure 3. Reporting time for each malaria patient $(n=25)$

The findings pertaining to timeliness, correctness, and completeness of the information received from volunteers are summarized in Table 2. The median reporting time was 0.2 hours, and only one case (4.0\%) was reported after the designated 24-hour period. On the other hand, all the variables were more than 95\% correct when cross-checked between reports. Similarly, all questionnaire items were at least $95 \%$ complete, with the exception of age, which was provided by only $84 \%$ of the patients. Finally, timeliness analyses revealed that, in $96 \%$ of cases, patients could be notified within 24 hours, while full completeness and completeness were $92 \%$ and $80 \%$, respectively (Figure 4).

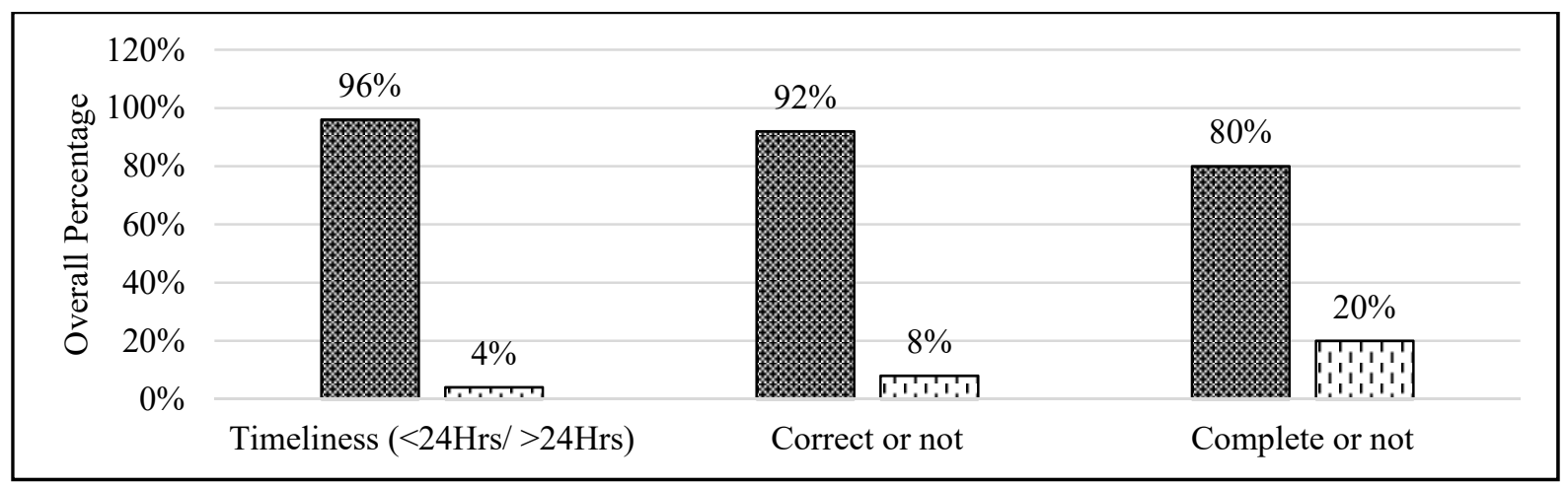

Figure 4. Overall percentage of Timeliness, Correctness and Completeness of the information $(n=25)$ 
Table 2. Timeliness, Correctness, Completeness of the information $(n=25)$

\begin{tabular}{|c|c|c|}
\hline Descriptions & Frequency & Percentage (\%) \\
\hline \multicolumn{3}{|l|}{ Timeliness } \\
\hline$<24$ Hours & 24 & 96.0 \\
\hline Median & 0.2 Hour & \\
\hline$>24$ Hours & 1 & 4.0 \\
\hline \multicolumn{3}{|l|}{ Correctness } \\
\hline \multicolumn{3}{|c|}{ Date \& time of diagnosis } \\
\hline Correct & 24 & 96.0 \\
\hline Incorrect & 1 & 4.0 \\
\hline \multicolumn{3}{|l|}{ Age } \\
\hline Correct & 23 & 92.0 \\
\hline Incorrect & 2 & 8.0 \\
\hline \multicolumn{3}{|l|}{ Sex } \\
\hline Correct & 25 & 100 \\
\hline Incorrect & 0 & 0 \\
\hline \multicolumn{3}{|l|}{ Species } \\
\hline Correct & 24 & 96.0 \\
\hline Incorrect & 1 & 4.0 \\
\hline \multicolumn{3}{|c|}{ Travelling History } \\
\hline Correct & 25 & 100 \\
\hline Incorrect & 0 & 0 \\
\hline \multicolumn{3}{|c|}{ Treatment Given } \\
\hline Correct & 25 & 100 \\
\hline Incorrect & 0 & 0 \\
\hline \multicolumn{3}{|c|}{ Completeness of Information } \\
\hline \multicolumn{3}{|c|}{ Date $\&$ time of diagnosis } \\
\hline Complete & 24 & 96.0 \\
\hline Incomplete & 1 & 4.0 \\
\hline \multicolumn{3}{|l|}{ Age } \\
\hline Complete & 21 & 84.0 \\
\hline Incomplete & 4 & 16.0 \\
\hline \multicolumn{3}{|l|}{ Sex } \\
\hline Complete & 24 & 96.0 \\
\hline Incomplete & 1 & 4.0 \\
\hline \multicolumn{3}{|l|}{ Species } \\
\hline Complete & 24 & 96.0 \\
\hline Incomplete & 1 & 4.0 \\
\hline \multicolumn{3}{|c|}{ Travelling History } \\
\hline Complete & 25 & 100 \\
\hline Incomplete & 0 & 0 \\
\hline \multicolumn{3}{|c|}{ Treatment Given } \\
\hline Complete & 24 & 96.0 \\
\hline Incomplete & 1 & 4.0 \\
\hline
\end{tabular}


When VMWs were asked to share their overall perceptions of this reporting system, $80 \%$ of the study sample suggested that it is simple and easy to utilize, while $90 \%$ of the respondents stated that they would accept implementation of this intervention. However, some individuals experienced difficulties using the application, such as poor signal $(20 \%)$, time consuming $(10 \%)$, and other challenges $(10 \%)$, as shown in Table 3.

Table 3. Simplicity, acceptability, preferences and challenges among 10 VMWs regarding intervention

\begin{tabular}{lll}
\hline Descriptions & Frequency & Percentage (\%) \\
\hline Simplicity & & \\
Yes & 2 & 80.0 \\
No & & 20.0 \\
Acceptability & 9 & \\
$\quad$ Yes & 1 & 90.0 \\
No & & 10.0 \\
Preferences & 10 & 100 \\
Like & 0 & 0 \\
Unlike & & \\
Challenges & 6 & 60.0 \\
Nil & 2 & 20.0 \\
Poor Signal & 1 & 10.0 \\
Time consuming & 1 & 10.0 \\
Others (Hearing Problem, etc.) & & \\
\hline
\end{tabular}

All the VMWs rated the system as reliable and felt that it was a viable reporting channel for timely notification of disease occurrence. Some of the reviews they provided following this qualitative study are summarized below:

'It was a great opportunity to learn such a new reporting system. As a result, I am more confident in treating my patients.'

'As network signal is sometimes terrible, I have to dial repeatedly and often have to call back three to four times.'

'To be honest, as malaria cases are becoming rarer, having one's mobile bill paid by the project is more than enough to promote the application use.'

'As not all people in this region know their exact age, we sometimes have to estimate.'

'Using the system is simple and a routine work, so I guess that we should continue using this reporting channel in the future.'

'I would say that I am overall satisfied with this kind of system, and have had no challenges using it.'

'We should call the hotline number as soon as we have found the patient, as we may otherwise forget.'

It is particularly noteworthy that all participants were satisfied with the training provided, as well as the routine monitoring visits from the township level and the telephone bill remuneration. Moreover, despite some challenges noted above, most respondents would be willing to continue using this intervention.

\section{Discussion}

With the exception of education level and ownership of a mobile phone, the distribution of the baseline demographic characteristics of the VMWs was similar. In remote areas of Myanmar, a primary level education is most common because those seeking further study must travel to a middle or high school, most of which are located in central, downtown regions. However, according to the national criteria, being a VMW requires only the ability to read and write (Chongsuvivatwong, 2012). In addition, before the system was introduced, all VMWs owned at least a functioning mobile phone (mobile networks were expanded across the Sagaing Region in 2017) (LIRNE Asia, 2017). During the study period, a total of 25 malaria patients were identified by VMWs, of which 24 were reported through the mobile phone reporting system within 24 hours. In addition to early diagnosis and 
treatment, such real-time reporting is the essential step needed to carry out further case classification and foci investigations as well as to conduct management activities to fulfil the goal of malaria elimination, i.e., to interrupt the progress of locally acquired transmission of the disease (WHO, 2015; WHO, 2016). A study conducted in Tanzania (Francis et al., 2017) and Kenya (Soti et al., 2015) suggested that real-time notification through a mobile phone or mobile application was a feasible and practical approach. However, as discrepancies can occur between report and actual data, a regular, intensive monitoring system must be implemented (Githinji et al., 2014). Public health staff should manage the work of VMWs and other volunteers in collaboration with relevant malaria health personnel. A proper national guide should be developed to assist in implementation of VMW-related interventions, including regular supervision of their activities.

In this study, satisfactory levels of data accuracy and completeness were noted. By using a simple and user-friendly version of the intervention, the providers appeared to adhere closely to the guidelines and directions (Prue et al., 2013; Quan, Hulth, Kok \& Blumberg, 2014). However, only (80\%) accuracy was noted in terms of the reporting of patient ages. This was likely due to the typical practice of the local residents, who are either unaware of their correct age or who calculate it incorrectly due to the complicated Myanmar calendar year. It would provide a significant advantage if exact census information could be gathered on all residents. In addition, typing errors were observed in reports of patient data, such as age, date and time of diagnosis, and species classification. These errors likely occurred because of the difficulty of typing on a smartphone. Such errors were most often committed by female VMWs as, in Myanmar, men are generally more accustomed to working with technological devices, such as mobile phones, tablets, and computers (LIRNE Asia, 2017). To evaluate the implemented system, a follow-up study was organized to explore the overall perceptions of the VMWs. Most described the manner of reporting as easy, acceptable, and feasible to continue. One related study, conducted in Bangladesh (Prue et al., 2013) and South Africa (Quan, Hulth, Kok \& Blumberg, 2014), also demonstrated the acceptability and ease of using a mobile phone reporting system. However, some challenges were reported, including concerns about network signals, prolonged reporting time, and other challenges, such as hearing difficulties. To overcome these issues, when the elimination continuum begins in this area, an alternative means of timely reporting, in addition to mobile phones and/or a traditional reporting system, should be secured. Moreover, other options for follow-up action should be made available to interrupt the transmission of malaria in the event of delayed notification. As it relates to network signals, these cannot be controlled, and it is hoped that signal strength will improve in the near future, as has been announced by the strategic plan (Post and Telecom Department, 2018).

During qualitative review, all of the VMWs described the system as reliable and useful, although they did mention some challenges. They also offered their preferences regarding an incentive scheme, monitoring visits, and training. To sustain both the intervention and VMW performance, there should be a regular incentive scheme, refresher trainings, regular monitoring, and a feedback system (Aung et al., 2018; Nyunt et al., 2016). Next, malaria and general health staff, with the support of VMWs, should develop materials and organize campaigns to inform communities about the availability of free malaria diagnosis and treatment at public health facilities as well as from VMWs to increase public usage of the service and avoid delayed reporting.

\section{Conclusions}

The results of this study demonstrate that the simple, efficient, and user-friendly mobile phone reporting system helps ensure timely and acceptable reporting of malaria cases by VMWs. For in-time disease notification purposes, this approach is better than more complicated, internet-based mobile applications. Regular monitoring should be implemented to address challenges with the completeness and accuracy of surveillance data. Some type of incentive scheme might be helpful in achieving better performance from the VMWs. The success of the reporting system notwithstanding, only a few indicators can be submitted using this mobile-based approach, and the system cannot be used in areas without adequate cellular network coverage. Future studies should expand the number of study participants and, if possible, compare them with the control villages. The sustainability issue should also be addressed by the consortium of health programmes, stakeholders, and local authorities as well as the donors. At the same time, it is important to exercise caution regarding overburdening the VMWs with the sudden introduction of new techniques and advanced tools.

\section{Funding}

This research was financially supported by the $90^{\text {th }}$ Anniversary of Chulalongkorn University, Rachadapisek Sompote Fund.

\section{Acknowledgements}

We would like to thank the Township Medical Officer and his Vector Borne Disease Control Team from study 
township for their kind cooperation on field implementation activities.

\section{Competing Interests Statement}

The Author(s) declare(s) that they have no conflicts of interest.

\section{References}

Aung, P., Silawan, T., Rawiworrakul, T., \& Min, M. (2018). Perceived role and its enhancing factors among the village health volunteers regarding malaria control in rural Myanmar. Indian journal of public health, 62(1), 10-10. https://doi.org/10.4103/ijph.IJPH_432_16

Cao, J., Sturrock, H. J., Cotter, C., Zhou, S., Zhou, H., Liu, Y., ... \& Gao, Q. (2014). Communicating and monitoring surveillance and response activities for malaria elimination: China's "1-3-7" strategy. PLoS medicine, 11(5), e1001642. https://doi.org/10.1371/journal.pmed.1001642

Chongsuvivatwong, V. (2012). Effects of malaria volunteer training on coverage and timeliness of diagnosis: a cluster randomized controlled trial in Myanmar. Malaria journal, 11(1), 309. https://doi.org/10.1186/1475-2875-11-309

Department of Public Health. Ministry of Health and Sports. (2016). National Strategic Plan in Myanmar (2016-2020).

Department of Public Health. Ministry of Health and Sports. (2016). National Plan for Malaria Elimination in Myanmar (2016-2030).

Feng, J., Liu, J., Feng, X., Zhang, L., Xiao, H., \& Xia, Z. (2016). Towards malaria elimination: monitoring and evaluation of the "1-3-7" approach at the China-Myanmar border. The American journal of tropical medicine and hygiene, 95(4), 806-810. https://doi.org/10.4269/ajtmh.15-0888

Francis, F., Ishengoma, D. S., Mmbando, B. P., Rutta, A. S., Malecela, M. N., Mayala, B., ... \& Michael, E. (2017). Deployment and use of mobile phone technology for real-time reporting of fever cases and malaria treatment failure in areas of declining malaria transmission in Muheza district north-eastern Tanzania. Malaria journal, 16(1), 308. https://doi.org/10.1186/s12936-017-1956-Z

Galpaya, H., Zainudeen, A., \& Suthaharan, P. (2015). A baseline survey of ICT and knowledge access in Myanmar. LIRNEasia, Colombo, Sri Lanka.

Githinji, S., Kigen, S., Memusi, D., Nyandigisi, A., Wamari, A., Muturi, A., ... \& Zurovac, D. (2014). Using mobile phone text messaging for malaria surveillance in rural Kenya. Malaria journal, 13(1), 107. https://doi.org/10.1186/1475-2875-13-107

Hamainza, B., Killeen, G. F., Kamuliwo, M., Bennett, A., \& Yukich, J. O. (2014). Comparison of a mobile phone-based malaria reporting system with source participant register data for capturing spatial and temporal trends in epidemiological indicators of malaria transmission collected by community health workers in rural Zambia. Malaria journal, 13(1), 489. https://doi.org/10.1186/1475-2875-13-489

Kamanga, A., Moono, P., Stresman, G., Mharakurwa, S., \& Shiff, C. (2010). Rural health centres, communities and malaria case detection in Zambia using mobile telephones: a means to detect potential reservoirs of infection in unstable transmission conditions. Malaria journal, $9(1), 96$. https://doi.org/10.1186/1475-2875-9-96

Kukula, V. A., Dodoo, A. A., Akpakli, J., Narh-Bana, S. A., Clerk, C., Adjei, A., ... \& Nikoi, C. (2015). Feasibility and cost of using mobile phones for capturing drug safety information in peri-urban settlement in Ghana: a prospective cohort study of patients with uncomplicated malaria. Malaria journal, 14(1), 411. https://doi.org/10.1186/s12936-015-0932-8

LIRNE Asia (2017). Towards a Networked Economy in Myanmar Report.

Meankaew, P., Kaewkungwal, J., Khamsiriwatchara, A., Khunthong, P., Singhasivanon, P., \& Satimai, W. (2010). Application of mobile-technology for disease and treatment monitoring of malaria in the "Better Border Healthcare Programme". Malaria journal, 9(1), 237. https://doi.org/10.1186/1475-2875-9-237

Myanmar Information Management Unit (2018). The MIMU 3W: Who is doing What, Where, Report.

Nyunt, M. H., Aye, K. M., Kyaw, K. T., Han, S. S., Aye, T. T., Wai, K. T., \& Kyaw, M. P. (2016). Challenges encountered by local health volunteers in early diagnosis and prompt treatment of malaria in Myanmar artemisinin resistance containment zones. Malaria journal, $15(1), \quad 308$. https://doi.org/10.1186/s12936-016-1368-5 
Phommanivong, V., Thongkham, K., Deyer, G., Rene, J. P., \& Barennes, H. (2010). An assessment of early diagnosis and treatment of malaria by village health volunteers in the Lao PDR. Malaria journal, 9(1), 347. https://doi.org/10.1186/1475-2875-9-347

Post and Telecom Department, Ministry of Transport and Communications (2018). Universal Service Strategy for Myanmar (2018-2022).

Prue, C. S., Shannon, K. L., Khyang, J., Edwards, L. J., Ahmed, S., Ram, M., ... \& Sack, D. A. (2013). Mobile phones improve case detection and management of malaria in rural Bangladesh. Malaria journal, $12(1), 48$. https://doi.org/10.1186/1475-2875-12-48

Quan, V., Hulth, A., Kok, G., \& Blumberg, L. (2014). Timelier notification and action with mobile phonestowards malaria elimination in South Africa. Malaria journal, 13(1), 151. https://doi.org/10.1186/1475-2875-13-151

Rassi, C., Gore-Langton, G. R., Walimbwa, B. G., Strachan, C. E., King, R., Basharat, S., ... \& Gudoi, S. S. (2018). Improving health worker performance through text messaging: A mixed-methods evaluation of a pilot intervention designed to increase coverage of intermittent preventive treatment of malaria in pregnancy in West Nile, Uganda. PloS one, 13(9), e0203554. https://doi.org/10.1371/journal.pone.0203554

Soti, D. O., Kinoti, S. N., Omar, A. H., Logedi, J., Mwendwa, T. K., Hirji, Z., \& Ferro, S. (2015). Feasibility of an innovative electronic mobile system to assist health workers to collect accurate, complete and timely data in a malaria control programme in a remote setting in Kenya. Malaria journal, 14(1), 430. https://doi.org/10.1186/s12936-015-0965-z

Wang, D., Cotter, C., Sun, X., Bennett, A., Gosling, R. D., \& Xiao, N. (2017). Adapting the local response for malaria elimination through evaluation of the 1-3-7 system performance in the China-Myanmar border region. Malaria journal, 16(1), 54. https://doi.org/10.1186/s12936-017-1707-1

World Health Organization [WHO]. (2012). Disease surveillance for malaria control: an operational manual.

World Health Organization [WHO]. (2015). Strategy for malaria elimination in the Greater Mekong Sub-region: 2015-2030.

World Health Organization [WHO]. (2016). Eliminating Malaria 2016. http://apps.who.int/iris/bitstream/handle/10665/205565/WHO_HTM_GMP_2016.3_eng.pdf?sequence=1

World Health Organization [WHO]. (2017). World malaria report 2016. World Health Organization.

Zainudeen, A., \& Galpaya, H. (2015). Mobile phones, internet, and gender in Myanmar. London, GSMA.

\section{Copyrights}

Copyright for this article is retained by the author(s), with first publication rights granted to the journal.

This is an open-access article distributed under the terms and conditions of the Creative Commons Attribution license (http://creativecommons.org/licenses/by/4.0/). 